\title{
Canalis sinuosus approximation on an impacted maxillary canine: a case report
}

\author{
Fahri Reza Ramadhan ${ }^{*}$, Dwi Putri Wulansari', Lusi Epsilawati
}

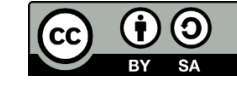

${ }^{1}$ Dentomaxillofacial Radiology Residency Program, Faculty of Dentistry, Universitas Padjadjaran, Bandung, Indonesia 40132

2 Department of Dentomaxillofacial Radiology, Faculty of Dentistry, Universitas Padjadjaran, Bandung, Indonesia 40132

*Correspondence to:

Fahri Reza Ramadhan

凶fahri19002@mail.unpad.ac.id

Received on: October 2021 Revised on: November 2021 Accepted on: December 2021

\section{ABSTRACT}

Objectives: This case report is aimed to report the finding of canalis sinuosus on an impacted maxillary canine using cone beam computed tomography (CBCT) examination.

Case Report: A 21-year-old male was referred from orthodontic department to radiology department UNPAD Dental Hospital for CBCT to determine the treatment of malalignment asymptomatic maxillary canine. The case revealed the presence of canalis that was identified as a canalis sinuosus, a branch of the anterior superior alveolar nerve that rarely known by a practitioner, at the apex of impacted right maxillary canine.

Conclusion: The information of this anatomical variation is important for professionals due to damage that may be caused during treatment. The use of advanced imaging examination is recommended to acknowledge the individual anatomical variation before determining the proper treatment planning.

Keywords: Canalis sinuosus, anatomy, impacted canine, CBCT Cite this article: Ramadhan FR. Wulansari DP, Epsilawati L. Canalis sinuosus approximation on an impacted maxillary canine: a case report. Jurnal Radiologi Dentomaksilofasial Indonesia 2021;5(3)118-21. https://doi.org/10.32793/ jrdi.v5i3.737

\section{INTRODUCTION}

The canalis sinuosus (CS) is a vital neurovascular canal but rarely reports in the literature. ${ }^{1,2}$ Jones in 1939, suggested the anatomical feature of CS and describing it as the nerve and blood vessels that leave the infraorbital nerve through the back section of the infraorbital foramen and pass laterally through a $2 \mathrm{~mm}$ diameter bone cana beside the nasal cavity. ${ }^{3,4}$ The term 'canalis sinuosus' refers to the double-curved course of its structure, which extends for roughly $55 \mathrm{~mm}$ through the maxilla.,

The superior posterior alveolar nerves, nasopalatine nerve, major palatine nerve, and infraorbital nerve are all branches of the trigeminal nerve. The skin and midface mucosa, as well as the accompanying artery and vein bundle, are al supplied by the infraorbital nerve. Infraorbital nerve medially bent to anterior wall of the maxillary sinus and passes along the infra-orbital foramen and has a lateral branch (canalis sinuosus), through which the anterior superior alveolar nerve passes. ${ }^{2,5,7,8}$ In some cases, the extend of CS in the osseus can form an accessory canal. From study conducted by Machado et al. (2016) it was found $52.1 \%$ from 1000 patients had accessory canal of CS and Aoki et al. (2019) found $66.5 \%$ of 206 patients had CS. ${ }^{7,9}$ In another study, Orhan K et al. (2017) found that 1034 patients (70.8\%) from 1460 had at least one accessory canal (AC) of canalis sinuosus. ${ }^{10}$
In the canine region, the dental plexus is formed by the neurovascular branches of the CS. CS enables sensibility of anterior teeth, nasal fossa floor and maxillary sinuses. Lack of understanding of CS and its accessory canal location can lead to pain, local infection, unexpected bleeding, and even paraesthesia during oral surgical procedures. ${ }^{7,10}$ Furthermore, many anatomy textbooks do not provide a detailed description of these variations. Professionals may mistakenly diagnose it as an infectious periapical disease. Using computed tomography to identify individual anatomical variations provides the surgeon more confidence and may assist avoid ineffective therapy or nerve damage during the surgical phase. ${ }^{10,11}$

Conventional imaging techniques such as periapical and panoramic radiography are frequently used as valuable diagnostic tools in dental practice. However, due to several limitations (superimpositions, magnifications, distortions, low image quality), these radiography techniques are often unable to define and reveal the anatomy of CS in detail. ${ }^{5,7,10}$ Due to its reduced radiation doses and increased diagnostic value for a wide range of clinical applications, cone beam computed tomography (CBCT) has become significantly more frequent in dental radiography over the last 15 years compared to standard computed tomography (CT). In addition, СВCT minimizes image overlap, 
allows for linear and angular measurements, and provides a multiplanar image reconstruction. ${ }^{2-4}$

\section{CASE REPORT}

A 21-year-old male patient was referred from Orthodontic Department to Radiology Department of Universitas Padjadjaran Dental Hospital, Bandung, Indonesia to evaluate and determine the treatment of malalignment right maxillary canine using $\mathrm{CBCT}$. The patient was in orthodontic treatment and wearing orthodontic appliances. Extra oral examination showed no facial asymmetry. Intra oral examination revealed an intruded right maxillary canine. CBCT showed an impacted tooth 13 with crown and root are in normal condition with the apical in mesial side associated with cavum nasal cortical while in dista side associated with maxillary sinus cortical. Apex side of the teeth was in approximation with a canal. The canal was seen from infraorbital. It went down mesially in between border of the maxillary sinus and cavum nasal and terminated at the palatal side of maxillary canine. The canal showed approximately $1,39 \mathrm{~mm}$ in diameter. This canal was identified later as a canalis sinuosus (CS). A diagnosis of impacted teeth 13 with cavum nasal, maxillary sinus and canalis sinuosus approximation was made.

\section{DISCUSSION}

For invasive dental procedures in maxilla, it is necessary for the clinicians to know the detail anatomy including canalis sinuosus (CS). The function of CS as a branch of infraorbital nerve is to aid in the sensitivity of anterior teeth, floor of nasal fossa and maxillary sinus. Shintaku et al. (2020)
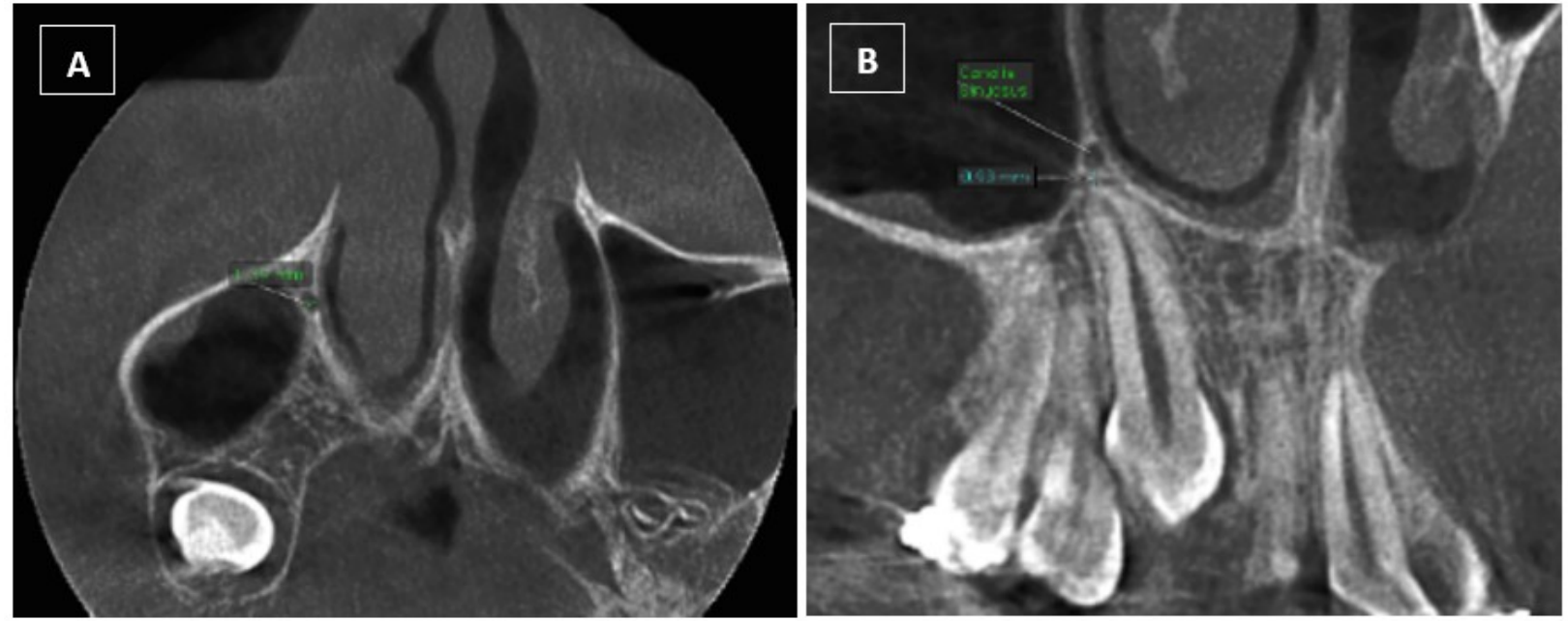

Figure 1. Reformatted axial plane (A) of CBCT showed the diameter of CS $1.39 \mathrm{~mm}$; reformatted coronal plane (B) of CBCT showed the location of CS and the distance to apical of right maxillary impacted canine.
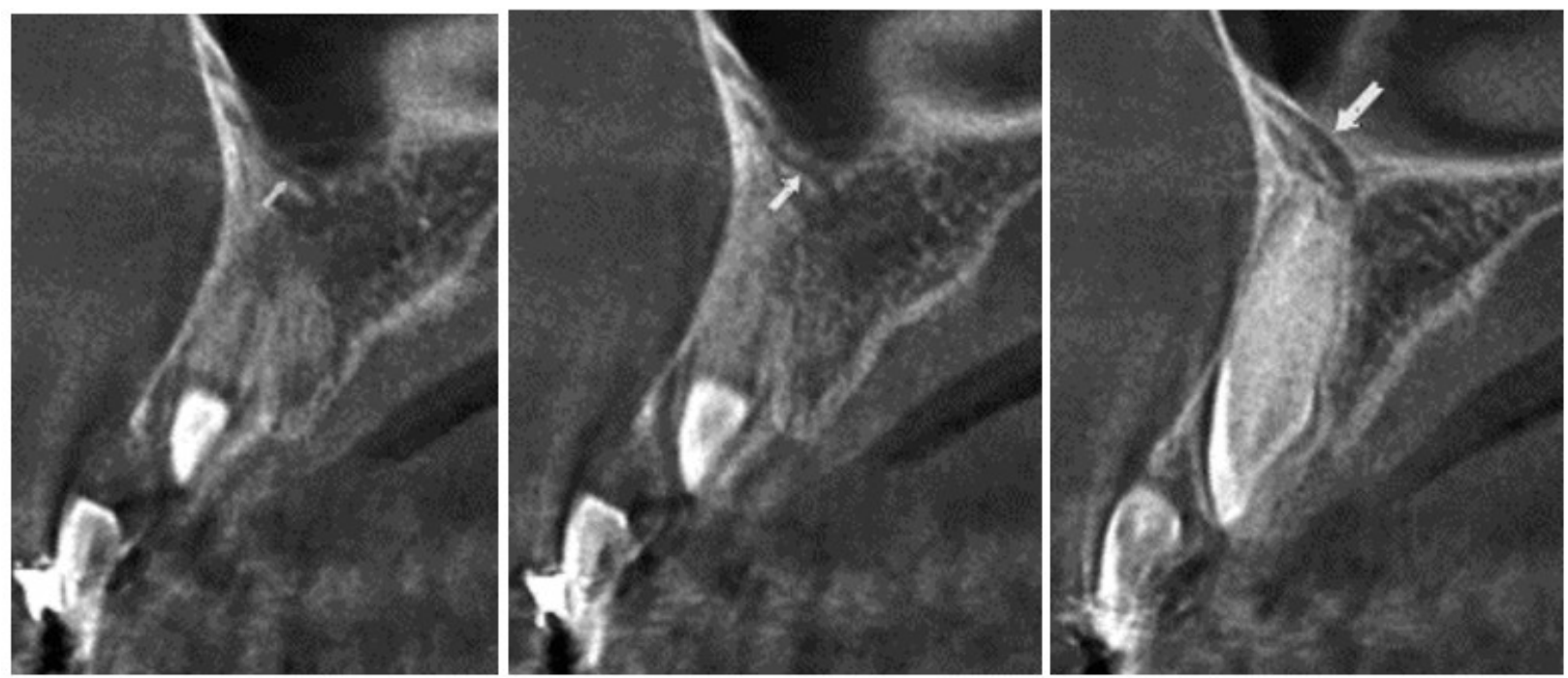

Figure 2. Reformatted sliced sagital plane showed the path of CS (white arrow) 

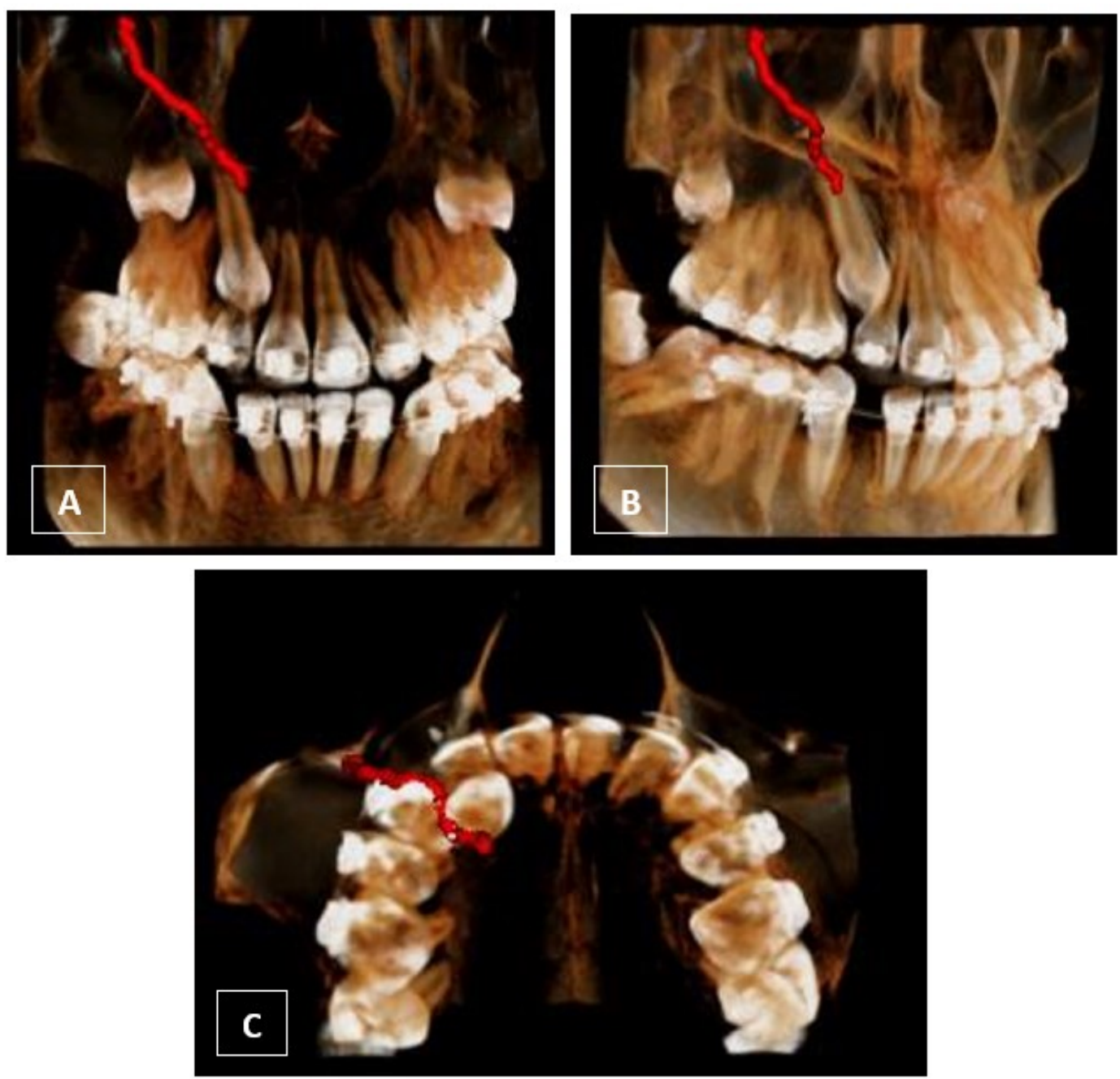

Figure 3. Three-dimensional teeth view in anterior (A), oblique (B) and occlusal (C) of CS tracing

reported an unexpected neurosensory disturbances and McCrea et al. (2017), reported an profuse postoperative nasal bleeding after insertion of implant in canine region of maxilla. ${ }^{12,13}$ Thus, the damage of any part of CS will certainly lead to problem in the affected area. ${ }^{7}$ The foramen and canals in the anterior superior maxillary region are relatively common, according to Oliveira-Santos et al., and dental surgeons must be aware and highly competent to identify these anatomical structure. ${ }^{4,14}$

Because of their small size, the accessory canal of CS is difficult to visualize using conventional radiography methods. The diameter of $A C$ is usually less than $1 \mathrm{~mm}$. In the present case, the diameter of CS was $1.39 \mathrm{~mm}$ (Figure.1B). Regarding to the study conducted by Gurler et al. (2017) which is evaluated the CS in patients with impacted canines, they found that the diameter of CS in male patient was in range of $1.22-1.82 \mathrm{~mm}^{15}$ Only few cases reported more than $2 \mathrm{~mm}$ of CS in diameter. Aoki et al. (2019) found that only seven (3.4\%) of 206 CBCT data had CS with diameter more than $1 \mathrm{~mm}$ and Machado et al. (2016) found that only $20 \%$ of 1000 CBCT data had a diameter $\geq 1 \mathrm{~mm}$. ${ }^{7,9}$ Gurler et al. (2017) found that the smallest distance from the CS to the impacted tooth was $0.75 \mathrm{~mm}$ with the average distance was $16.81 \mathrm{~mm}$. This was in line with the present case that had $0.93 \mathrm{~mm}$ (Figure.1A) distance from CS to apical of impacted canine. Due to this small distance, the canal may be injured during surgical phase, especially in the removal of impacted canine. The clinicians should pay more attention to this finding.

Porous cortical layers and a varied course have also been indicated as a diagnostic challenge in conventional radiography approaches. ${ }^{5} \mathrm{CBCT}$ is the best modality for determining the location of CS, making it extremely important for patient diagnosis and evaluation. The use of CBCT to analyse CS is more valuable than 2-dimension modality because the conventional radiography often unable to distinguish and display this structure in detail. Individualization and visualization of the CS along its course in three dimensions: axial, coronal, and sagittal are possible with the $\mathrm{CBCT}$. ${ }^{7,15,16}$

In study conducted by Machado et al. (2016) and Von Arx et al.(2013) was found that males have a higher prevalence of CS than females. ${ }^{9,17}$ This was in line with our present case that reported a male patients. On the other hand, no relationship between the AC presence of CS and patient's age was found in study conducted by Oliveira-Santos et al. (2013), Wanzeler et al. (2014), and Salli et al. 
(2021)..$^{7,11,16}$

In present case, the end of accessory canals of CS were located palatal to the impacted canine. This was in line with the study conducted by Von Arx et al. (2013) that was found that the terminal portions of CS were found $91.1 \%$ palatal to the anterior maxillary teeth, and corroborated by the found of Oliveira-Santos et al. (2013) which is stated that the most of accesory canal of CS occurring in the alveolar process near the incisors or canines. ${ }^{14,17}$

The evaluation of CS in patients with maxillary impacted canines was conducted by Gurler et al. (2017). They found that $100 \%$ of 111 patients with impacted canine had CS and almost all the CS of the samples terminated near the incisive canal on the nasal floor. From 111 patients, only 6 patient was reported had accessory canal of CS with the most common location was palatal to the lateral incisors. ${ }^{15}$ The limitation of this study is that the research was done in Turkish population, that may be different with population in Indonesia.

\section{CONCLUSION}

Canalis sinuosus is currently reported not only as an anatomical variation but also as a common anatomic structure in the anterior maxilla which in some cases can extend to form an accessory canal. Both the canal and the accessory are hard to distinguish on 2D radiographs and often ignored by the clinicians. Therefore, knowing of this canal and considering CBCT as the gold standard of CS screening before any surgical in anterior maxilla are needed to avoid the damaging of CS and other neurovascular bundles. Beside that, CS finding in Indonesian population is limited and still need to be reported.

\section{ACKNOWLEDGMENTS}

None.

\section{FOOTNOTES}

All authors have no potential conflict of interest to declare for this article. Informed consent was obtained from the patient for being included in this case report.

\section{REFERENCES}

1. Arruda JA, Silva P, Silva L, Álvares P, Silva L, Zavanelli R, et al. Dental Implant in the Canalis Sinuosus: A Case Report and Review of the Literature Case Reports in Dentistry. 2017:1-6.

2. Lello RIE, Bornstein MM, Suter VGA, Bischof FM, von Arx T. Assessment of the anatomical course of the canalis sinuosus using cone beam computed tomography. Oral Surgery. 2020;13(3):221-9.

3. Ferlin R, Pagin BSC, Yaedú RYF. Canalis sinuosus: a systematic review of the literature. Oral Surgery Oral Medicine Ora Pathology and Oral Radiology. 2019;127(6):545-51.

4. Manhães Júnior LRC, Villaça-Carvalho MFL, Moraes MEL,
Lopes SLP de C, Silva MBF, Junqueira JLC. Location and classification of Canalis sinuosus for cone beam computed tomography: avoiding misdiagnosis. Brazilian Oral Research. 2016;30(1):e49.

5. Tomrukçu DN, Köse TE. Assesment of accessory branches of canalis sinuosus on CBCT images. Medicina Oral Patologia Oral y Cirugia Bucal. 2020;25(1):e124-30.

6. Torres MGG, de Faro Valverde L, Vidal MTA, Crusoé-Rebello IM. Branch of the canalis sinuosus: a rare anatomical variation-a case report. Surgical and Radiology Anatomy. 2015;37(7):879-81.

7. Aoki R, Massuda M, Zenni LTV, Fernandes KS. Canalis sinuosus: anatomical variation or structure?. Surgical and Radiology Anatomy. 2020;42(1):69-74.

8. Neves FS, Crusoé-Souza M, Franco LCS, Caria PHF, BonfimAlmeida P, Crusoé-Rebello I. Canalis sinuosus: A rare anatomical variation. Surgical and Radiology Anatomy. 2012;34(6):563-6.

9. Machado V de C, Chrcanovic BR, Felippe MB, Manhães Júnior LRC, de Carvalho PSP. Assessment of accessory canals of the canalis sinuosus: a study of 1000 cone beam computed tomography examinations. International Journal of Oral and Maxillofacial Surgery. 2016;45(12):1586-91.

10. Orhan K, Gorurgoz C, Akyol M, Ozarslanturk S, Avsever H. An anatomical variant: Evaluation of accessory canals of the canalis sinuosus using cone beam computed tomography. Folia Morphologica. 2018;77(3):551-7.

11. Wanzeler AMV, Marinho CG, Junior SMA, Manzi FR, Tuji FM. Anatomical study of the canalis sinuosus in 100 cone beam computed tomography examinations. Oral and Maxillofac Surgery. 2015;19(1):49-53.

12. Shintaku $\mathrm{WH}$, Ferreira CF, Venturin J de S. Invasion of the canalis sinuosus by dental implants: A report of 3 cases. Imaging Science in Dentistry. 2020;50(4):353-7.

13. Mccrea SJJ. Aberrations Causing Neurovascular Damage in the Anterior Maxilla during Dental Implant Placement. Case Reports in Dentistry. 2017;2017: 5969643.

4. De Oliveira-Santos C, Rubira-Bullen IRF, Monteiro SAC, León $J E$, Jacobs R. Neurovascular anatomical variations in the anterior palate observed on $\mathrm{CBCT}$ images. Clinical Oral Implants Research. 2013;24(9):1044-8.

15. Gurler G, Delilbasi C, Ogut EE, Aydin K, Sakul U. Evaluation of the morphology of the canalis sinuosus using cone-beam computed tomography in patients with maxillary impacted canines. Imaging Science in Dentistry. 2017;47(2):69-74.

16. Salli GA, Öztürkmen Z. Evaluation of Location of Canalis Sinuosus in the Maxilla Using Cone Beam Computed Tomography. Balkan Journal of Dental Medicine. 2021;25(1):7 -12 .

17. Von Arx T, Lozanoff S, Sendi P, Bornstein MM. Assessment of bone channels other than the nasopalatine canal in the anterior maxilla using limited cone beam computed tomography. Surgical and Radiologic Anatomy. 2013;35 (9):783-90. 